\title{
Exploring the Serum Level of RE1 Silencing Transcription Factor in Alzheimer's Disease
}

\author{
${ }^{1}$ Department of Biophysics, All India Institute of Medical Sciences, \\ New Delhi, India \\ ${ }^{2}$ Department of Neurology, All India Institute of Medical Sciences, \\ New Delhi, India \\ ${ }^{3}$ Department of Geriatric Medicine, All India Institute of Medical \\ Sciences, New Delhi, India
}

Shashank Shekhar ${ }^{1}$ Manjari Tripathi ${ }^{2}$ A.B. Dey ${ }^{3}$ Sharmistha Dey ${ }^{3}$

\begin{abstract}
Address for correspondence Sharmistha Dey, PhD, Department of Biophysics, All India Institute of Medical Sciences, New Delhi 110029, India (e-mail: sharmistha_d@hotmail.com).
\end{abstract}

Ann Natl Acad Med Sci (India) 2022;58:22-26.

\author{
Abstract \\ Keywords \\ - Alzheimer's disease \\ - serum RE1 silencing \\ transcription factor \\ - mild cognitive \\ impairment \\ - surface plasmon \\ resonance
}

Objective The aim of this study was to evaluate the serum RE1 silencing transcription factor (REST) level in Alzheimer's disease (AD), mild cognitive impairment ( $M C l)$, and elderly controls by using surface plasmon resonance (SPR) technology.

Materials and Methods In this case-control study of 133 subjects, 49 patients with $\mathrm{AD}, 49$ patients with $\mathrm{MCl}$, and 35 elderly controls were recruited. The REST protein concentrations were evaluated by SPR. The resonance unit for each sample was recorded and the concentration of serum REST of study group was derived from the standard curve. All the experiments were done in triplicates. Statistical analysis was done and $p$-value of $<0.05$ was considered as statistically significant.

Results A significant difference was observed in the Montreal Cognitive Assessment score, Hindi Mental State Examination scale (HMSE) score education, disease duration, and gender among the groups. A significant $(p>0.0001)$ difference in the duration of disease between $A D$ and $\mathrm{MCl}$ was observed. It was observed that the mean concentration of serum REST was not significantly $(p=0.266)$ different among the groups. Conclusion This study first time evaluated the serum levels of REST in $A D, M C l$ and age-matched elderly controls. The rest levels were similar in all groups; however, it can provide a new direction to future blood-based biomarker studies of REST.

\section{Introduction}

Worldwide more than 35.6 million people and in India more than 3.7 million people have Alzheimer's disease (AD). AD causes worsening of memory and other cognitive domains that lead to death within 3 to 9 years after diagnosis ${ }^{1-3}$ due to lack of proper diagnosis that results in lack of treatment and medication. It is a progressive neurodegenerative disorder that is often manifested by cognitive and memory im- pairment. It is also an impairment of daily activities, and neuropsychiatric complications including behavioral disturbances. Among all the dementia, AD is most common and accounts for 50 to $56 \%$ of the autopsy results and in clinical sequence. This huge demographic data shows status of socioeconomic burden worldwide. Due to the dependency on caregivers, it is also pathetic for family and caregivers. So, there is an urgent need for the research and identification of plausible biomarker candidate that could be easily accessible published online November 8, 2021
DOI https://doi.org/ 10.1055/s-0041-1731970. ISSN 0379-038X.

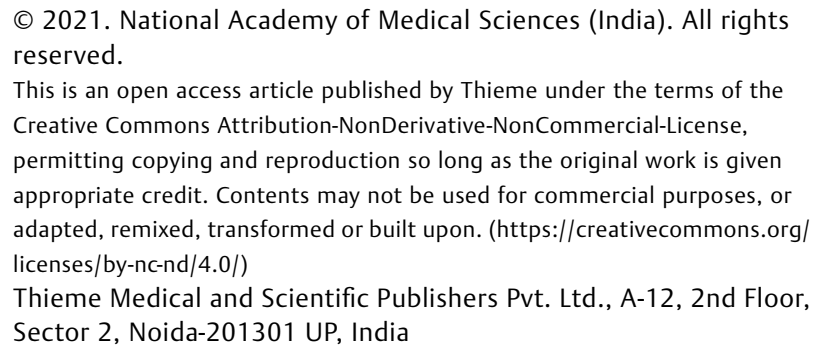

(C) 2021. National Academy of Medical Sciences (India). All rights reserved.

This is an open access article published by Thieme under the terms of the Creative Commons Attribution-NonDerivative-NonCommercial-License, permitting copying and reproduction so long as the original work is given appropriate credit. Contents may not be used for commercial purposes, or adapted, remixed, transformed or built upon. (https://creativecommons.org/ licenses/by-nc-nd/4.0/)

Thieme Medical and Scientific Publishers Pvt. Ltd., A-12, 2nd Floor, Sector 2, Noida-201301 UP, India 
and accurate for the detection of $\mathrm{AD}$ and mild cognitive impairment (MCI).

RE 1 silencing transcription factor (REST) is also known as the neuron-restrictive silencer factor and plays important role in the neurogenesis and various neurological diseases. How the neurons of hippocampus and cortex region remain preserved from stress and toxic insult in healthy aging is questionable, while in AD neuronal loss is evident in these regions. Both the cases, in normal and $A D$, are unclear. Lu et al have shown the role of REST in neuroprotection. ${ }^{4}$ Authors performed various experiments including bioinformatics analysis of gene expression profiling, and in the autopsy, brain tissues of adult, aging, $\mathrm{MCI}$, and AD. They showed that REST is high during aging as compared with adults and lower in $\mathrm{MCI}$ and almost absent in case of $A D$ patients. This finding highlighted the role of REST in aging and $\mathrm{AD}$ brain and showed that REST regulates various genes of cell death pathway that have crucial role in the AD pathogenesis. The toxic insults in brain lead to activation of some protective mechanism, and REST is reported as a neuroprotective molecule. ${ }^{4}$ Loss of neuroprotective function of REST contributes to neurodegeneration in the AD brains. REST provides transcriptional repression of several proapoptotic genes as well as certain genes that encode enzymes involved in pathology of $\mathrm{AD}$. It provides resistance to neurotoxic stress in aging brain. In case of $A D$, this function is lost as REST is diverted from nucleus to the autophagy pathway where it gets degraded. ${ }^{4}$ REST can be induced by Wnt-3a and Wnt-7a (two proteins from the Wnt family), and that a Wnt-receptor antagonist partially inhibits REST induction. These results suggest that stress can increase Wnt signaling, which, in turn, induces REST expression. This finding emphasizes the importance of REST in AD pathology and creates need of evaluation of REST level in the bloodstream, rather than just in autopsied brain tissue, to have clinical implications. In animal models, they have also shown that genetic depletion of REST resulted in augmented neurodegeneration in hippocampus and the cortex. In 2015, Nho et al, also highlighted the importance of REST in AD. ${ }^{5}$ Keeping these points in mind here in this study we have evaluated the serum REST level in $\mathrm{AD}, \mathrm{MCI}$ and elderly controls by using surface plasmon resonance (SPR) technology.

\section{Materials and Methods}

\section{Patients and Control}

In this case-control study of 133 subjects, 49 patients with $\mathrm{AD}, 49$ patients with $\mathrm{MCI}$, and 35 elderly controls were recruited from the Geriatric Medicine Memory Clinic and Neurology OPD of All India Institute of Medical Sciences (AIIMS), New Delhi, India. The study protocol was approved by Ethics Committee of AIIMS (IESC/T-439/23.12.2014). Informed consent was obtained from controls, patients, or their attendants (if patient is unable of making a signature). The dementia was diagnosed by a two-step diagnostic process. Older subjects with subjective cognitive complaints were first screened for cognitive impairment with Hindi Mental State Examination scale (HMSE; scores $<24$ out of $30)^{6}$ and Montreal Cognitive Assessment (MoCA; score $<22$ out of 30$)^{7}$ Consequently, they were subjected to compre- hensive evaluation including neurological examination, brain imaging, routine laboratory tests to exclude reversible causes of dementia, assessment of activities of daily living, and neuropsychological testing (Clinical Dementia Rating Scale and the Blessed Dementia rating Scale) for the categorization of dementia. A NINCDS-ADRDA criterion was used to diagnose $\mathrm{AD}^{8} \mathrm{MCI}$ was diagnosed in presence of MoCA scores 18 to 26 and status of dependence for activities of daily living. Older individuals in good health (no obvious disease or disability in clinical examination) with normal HMSE and MoCA scores were invited to participate in the study as controls. Samples were processed according to the guidelines for the preanalytical methods. ${ }^{9}$

\section{Evaluation of Serum Level of REST in AD, MCI Patients, and Elderly Controls by SPR}

The REST protein concentrations were evaluated by SPR. All SPR quantifications were performed at $25^{\circ} \mathrm{C}$ using the BIAcore-3000 (Wipro, GE Healthcare, Uppsala, Sweden) that is a biosensor-based system for real-time specific interaction analysis. The antibody was immobilized on the CM5 sensor chip using the amine coupling kit as described earlier. ${ }^{10}$

The standard curve was prepared by passing different concentrations $(0.2,0.5,1.01,1.42,3.44,4.05,4.46$, and $5.07 \mathrm{ng} / \mu \mathrm{L})$ of purified recombinant human REST protein over the immobilized antibody on respective flow cell and corresponding resonance units (RU) were obtained. REST protein was cloned, expressed, and purified in bacterial system as described earlier. ${ }^{10,11}$ Serum samples were diluted (1:70) with HEPES buffered saline with $30 \mathrm{mM}$ EDTA (ethylenediaminetetraacetic acid) and $0.5 \%(\mathrm{v} / \mathrm{v}$ ) surfactant P20 buffer and passed over the immobilized antibody in respective flow cell. The RU for each sample was recorded and the concentration of serum REST of patients and elderly controls was derived from the standard curve. All the experiments were done in triplicates.

\section{Statistical Analysis}

Data analysis was done by Stata/SE version 9 and GraphPad prism5 (College Station, Texas, United States and GraphPad Software, Inc., La Jolla, California, United States). Descriptive analysis was performed for all variables and with percentages or mean and standard deviation. Baseline comparison among geriatric controls (GC), $\mathrm{MCI}$, and $\mathrm{AD}$ patients was made using appropriate statistical tests: for categorical variables, chisquared test was used and continuous variables were compared among groups using one-way analysis of variance followed by post hoc comparison using the Bonferroni test. Pearson's correlation coefficient $(r)$ of REST in serum level with demographic data among the study groups was determined. The $p$-value of $<$ 0.05 was considered as statistically significant.

\section{Results}

\section{Patients and Control}

Significant differences were observed in the median MoCA score, median HMSE score education, disease duration, and gender among the groups (-Table1). The proportion of males was more in study groups. 
24 Serum REST Levels in AD Shekhar et al.

Table 1 Demographic data of study groups

\begin{tabular}{|c|c|c|c|c|}
\hline & $\mathrm{AD}(n=49)$ & $\mathrm{MCl}(n=49)$ & Control $(n=35)$ & $p$-Value \\
\hline \multicolumn{5}{|l|}{ Gender } \\
\hline Male & 28 & 40 & 26 & \multirow[t]{2}{*}{0.025} \\
\hline Female & 21 & 9 & 09 & \\
\hline Average age $( \pm S D)$ & $67.32 \pm 7.6$ & $6873 \pm 7.1$ & $69.42 \pm 7.03$ & 0.39 \\
\hline Average disease duration in years $( \pm S D)$ & $3.55 \pm 1.48$ & $1.33 \pm 0.66$ & - & $>0.0001$ \\
\hline \multicolumn{5}{|l|}{ Living status } \\
\hline Rural & 17 & 10 & 9 & \multirow[t]{2}{*}{0.289} \\
\hline Urban & 32 & 39 & 26 & \\
\hline \multicolumn{5}{|l|}{ Education in years } \\
\hline $0-5$ & 14 & 7 & 10 & \multirow[t]{4}{*}{0.002} \\
\hline $6-10$ & 15 & 9 & 8 & \\
\hline $11-15$ & 11 & 9 & 13 & \\
\hline $16+$ & 9 & 24 & 4 & \\
\hline HMSE, median with min-max (out of 30 ) & $12(0-23)$ & $25(18-28)$ & $29(27-30)$ & $>0.0001$ \\
\hline MoCA median with min-max (out of 30 ) & $8(0-22)$ & $21(14-28)$ & $28(26-30)$ & $>0.0001$ \\
\hline
\end{tabular}

Abbreviations: AD, Alzheimer's disease; HMSE, Hindi Mental State Examination; MCI, mild cognitive impairment; MoCA, Montreal Cognitive Assessment, SD, standard deviation.

A significant $(>0.0001)$ difference in the duration of disease between $\mathrm{AD}$ and $\mathrm{MCI}$ was observed. Most of the patients participated in the study were urban and are educated above 16 years.

\section{Evaluation of Serum Level of REST by SPR}

The RU value after immobilization of antibody was 15589.5 , where $1 \mathrm{RU}$ corresponds to $1 \mathrm{pg} / \mathrm{mm}$ (-Fig. 1A). The standard curve was plotted with RU obtained from different

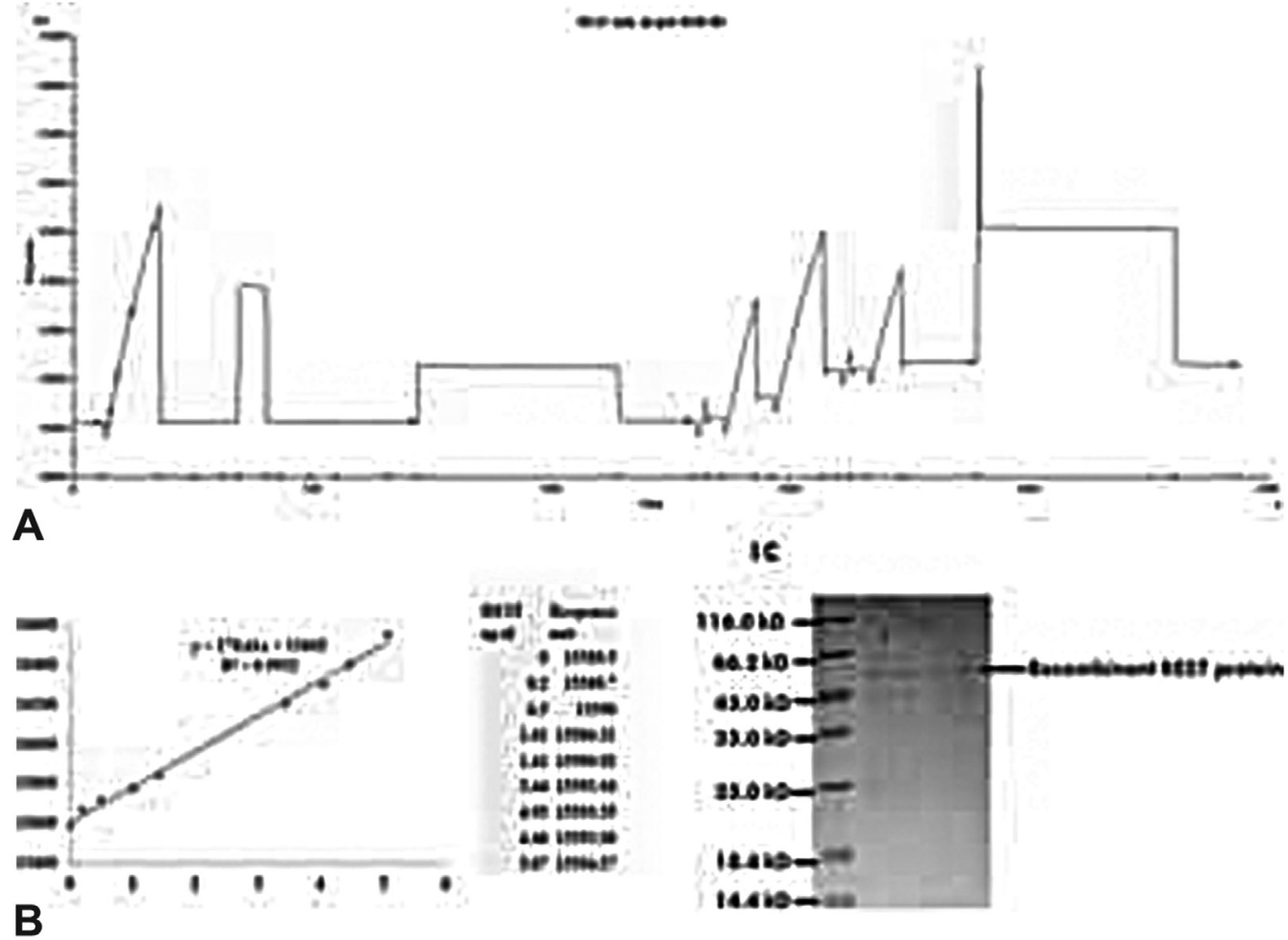

Fig. 1 (A) Immobilization of anti-RE-1-silencing transcription factor (REST) antibody on CM5 sensor chip by using amine coupling kit. (B) SDSPAGE gel of purified recombinant REST protein. 


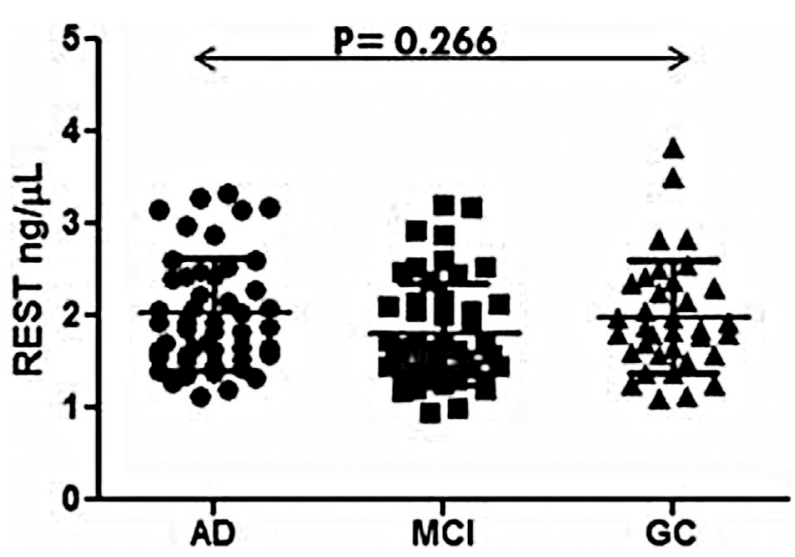

Fig. 2 Scattered graph of serum level of RE-1-silencing transcription factor (REST) in Alzheimer's disease (AD), mild cognitive impairment $(\mathrm{MCl})$ and elderly control groups. concentrations of recombinant REST ( - Fig. 1B). The binding of the REST ligands was in the linear range. In the present study, we examined the level of REST in the serum of $\mathrm{AD}, \mathrm{MCI}$, and elderly control patients. It was observed that the mean concentration of serum REST was not significantly ( $p=0.266$ ) different among three groups. The values obtained were, in case of controls, $1.98 \pm 0.59 \mathrm{ng} / \mu \mathrm{L}$ as compared with $\mathrm{MCI}$ $(1.89 \pm 0.57 \mathrm{ng} / \mu \mathrm{L})$ and $\mathrm{AD}$ patients $(2.11 \pm 0.62 \mathrm{ng} / \mu \mathrm{L})$ (-Fig. 2).

No significant difference in the serum REST level was observed between different gender (male and female) and age (60-70 years and $>70$ years) (-Table 2 , - Fig. $\mathbf{3}$ ).

Pearson's correlation coefficient $(r)$ of REST serum level with demographic data among the study groups is illustrated in - Table 3. No significant difference was observed between the demographic data of the study groups.

Table 2 Correlation of serum REST by age and gender wise

\begin{tabular}{|c|c|c|c|c|}
\hline & $A D$ & $p$-Value & $\mathrm{MCl}$ & $p$-Value \\
\hline Male & $2.080 \mathrm{ng} / \mu \mathrm{L}$ & \multirow[t]{2}{*}{0.412} & $1.866 \mathrm{ng} / \mu \mathrm{L}$ & \multirow[t]{2}{*}{0.119} \\
\hline Female & $1.936 \mathrm{ng} / \mu \mathrm{L}$ & & $1.544 \mathrm{ng} / \mu \mathrm{L}$ & \\
\hline Age $60-70 y$ & $1.943 \mathrm{ng} / \mu \mathrm{L}$ & \multirow[t]{2}{*}{0.170} & $1.825 \mathrm{ng} / \mu \mathrm{L}$ & \multirow[t]{2}{*}{0.856} \\
\hline Age $70 y+$ & $2.205 \mathrm{ng} / \mu \mathrm{L}$ & & $1.796 \mathrm{ng} / \mu \mathrm{L}$ & \\
\hline
\end{tabular}

Abbreviations: AD, Alzheimer's disease; MCl, mild cognitive impairment; REST, RE-1-silencing transcription factor.

Table 3 Pearson's correlation coefficient ( $r$ ) of REST serum level with demographic data among the study groups

\begin{tabular}{|c|c|c|c|c|c|c|}
\hline Control $(r)$ & $p$-Value & $\mathrm{MCl}(r)$ & $p$-Value & $\mathrm{AD}(r)$ & $p$-Value & \\
\hline Age & 0.1539 & 0.377 & 0.0097 & 0.947 & 0.2093 & 0.148 \\
\hline Gender & 0.2550 & 0.139 & 0.2252 & 0.119 & 0.1197 & 0.412 \\
\hline Education & 0.0531 & 0.761 & 0.1353 & 0.353 & 0.0133 & 0.928 \\
\hline Disease duration & - & - & 0.2154 & 0.137 & 0.0508 & 0.729 \\
\hline HMSE & 0.0508 & 0.771 & 0.0462 & 0.752 & 0.0237 & 0.871 \\
\hline MoCA & 0.3899 & 0.020 & 0.0748 & 0.609 & 0.0977 & 0.504 \\
\hline
\end{tabular}

Abbreviations: AD, Alzheimer's disease; MCI, mild cognitive impairment; REST, RE-1-silencing transcription factor.

\section{Ao pandur wise}

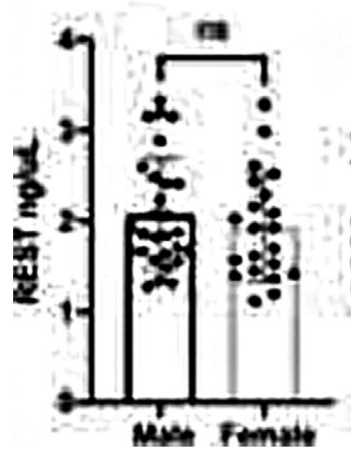

MCl gondor witse

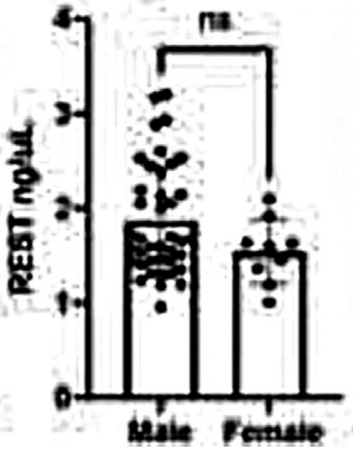

AD Age Wiso

MCt Age Wise
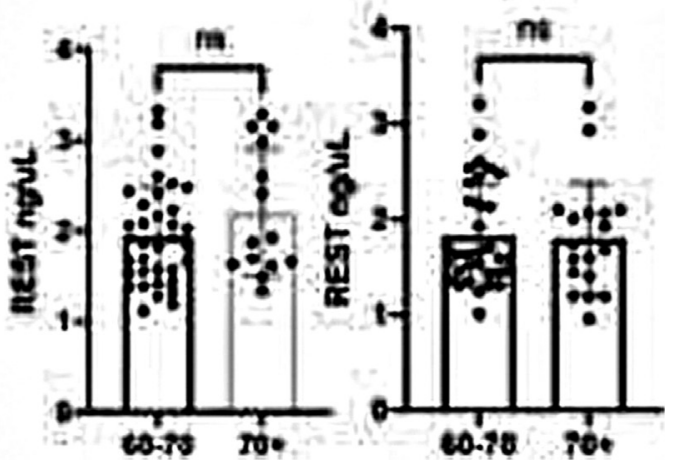

Fig. 3 Level of serum RE-1-silencing transcription factor (REST) in Alzheimer's disease (AD) and mild cognitive impairment (MCI) in age and gender wise. 


\section{Discussion}

Some studies have shown the importance of REST in the AD and $\mathrm{MCI}$ and it is also emphasized that it could be responsible for healthy aging. ${ }^{4}$ Meyer et al $2019^{12}$ reported that epigenetic dysregulation and change in neuron differentiation partly arbitrate by REST protein that accumulate $p$-tau and aggregate $\beta$-amyloid in AD pathology. The protein studies of expression of REST pathway in AD was reported from the autopsy brain tissue. Here in this study, we have explored the expression of REST protein serum level for AD. But unfortunately, we have not observed any statistically significant difference in the serum level of REST among AD, $\mathrm{MCl}$, and elderly control. Some recent study has shown lower plasma levels of plasma derive exosomes/neuronal derived exosomes. ${ }^{13,14}$ Exosomes are released from variety of cells, including neuronal cells. ${ }^{15}$ Exosomes have been shown to play important role in neuronal development and regeneration ${ }^{16}$ and they have been involved in transport of pathogenic proteins in the brain and in progression of neurodegenerative disease. ${ }^{17}$ These results provide a possible clue for the nonsignificant serum level of REST among $\mathrm{AD}, \mathrm{MCI}$, and elderly controls. At this point, we assume that we get no difference in serum level due to packaging of the protein into the extracellular vesicle, that is, neuronal exosomes. The packaging may result in the inaccessibility of protein in exosomes to antibody that is covalently immobilized on the CM5 sensor chip of the SPR. We also assume that the level that we get in serum could be from different cell types as the data from other group shows the packaging of REST in extracellular vesicles. Our result provides a new direction for the development of new methods that could release the content of extracellular vesicles for the quantification from specifically purified neuronal exosomes.

\section{Conclusion}

This study first time evaluated the serum level of REST and can provide a new direction to future blood-based biomarker studies of REST. Even after its presence in the serum, it could not differentiate $\mathrm{AD}$ and $\mathrm{MCI}$ from elderly controls. From our results, we can conclude that serum level of REST could not be a good marker candidate for AD diagnosis.

\section{Authors' Contributions}

S.S. performed the experimental work and wrote the manuscript; A.B.D. and M.T. provided the patients samples, and S.D. designed the work and edited the manuscript.

\section{Conflict of Interest \\ None declared.}

\section{Acknowledgments}

The authors acknowledge All India Institute of Medical Sciences and CSIR, Government of India, for the fellowship of Shashank Shekhar. REST clone was a provided by Professor Gerald Thiel, University of Saarland Medical Center, Germany, to whom the authors are thankful.

\section{References}

1 Jotheeswaran A, Girish N, et al. The Dementia India Report: Prevalence, Impact, Costs and Services for Dementia. Executive Summary. New Delhi, India: Alzheimer's and Related Disorders Society of India (ARDSI); 2010

2 Querfurth HW, LaFerla FM. Alzheimer's disease. N Engl J Med 2010;362(04):329-344

3 Lodato E. Priority Medicines for Europe and the World "A Public Health Approach to Innovation" Update on the 2004 Background Paper.. 13; 1-122

4 Lu T, Aron L, Zullo J, et al. REST and stress resistance in ageing and Alzheimer's disease. Nature 2014;507(7493)448-454

5 Nho K, Kim S, Risacher SL, et al.MIRAGE (Multi-Institutional Research on Alzheimer Genetic Epidemiology) Study AddNeuroMed Consortium Indiana Memory and Aging Study Alzheimer's Disease Neuroimaging Initiative. Protective variant for hippocampal atrophy identified by whole exome sequencing. Ann Neurol 2015;77(03):547-552

6 A Hindi version of the MMSE: The development of a cognitive screening instrument for a largely illiterate rural elderly population in India - Ganguli - 1995 - International Journal of Geriatric Psychiatry - Wiley Online Library. Available at:https://onlinelibrary.wiley.com/doi/abs/10.1002/gps.930100505. Accessed June 16, 2021

7 O'Caoimh R, Timmons S, Molloy DW. Screening for mild cognitive impairment: comparison of "MCI Specific" screening instruments. J Alzheimers Dis 2016;51(02):619-629

8 McKhann G, Drachman D, Folstein M, Katzman R, Price D, Stadlan EM. Clinical diagnosis of Alzheimer's disease: report of the NINCDS-ADRDA Work Group under the auspices of Department of Health and Human Services Task Force on Alzheimer's Disease. Neurology 1984;34(07):939-944

9 O'Bryant SE, Gupta V, Henriksen K, et al. STAR-B and BBBIG working groups. Guidelines for the standardization of preanalytic variables for blood-based biomarker studies in Alzheimer's disease research. Alzheimers Dement 2015;11(05):549-560

10 Shekhar S, Yadav SK, Rai N, et al. 5-LOX in Alzheimer's disease: potential serum marker and in vitro evidences for rescue of neurotoxicity by its inhibitor YWCS. Mol Neurobiol 2018;55 (04):2754-2762

11 Thiel G, Lietz M, Cramer M. Biological activity and modular structure of RE-1-silencing transcription factor (REST), a repressor of neuronal genes. J Biol Chem 1998;273(41):26891-26899

12 Meyer K, Feldman HM, Lu T, et al. REST and neural gene network dysregulation in iPSC models of Alzheimer's disease. Cell Rep 2019;26(05):1112-1127.e9

13 Goetzl EJ, Boxer A, Schwartz JB, et al. Low neural exosomal levels of cellular survival factors in Alzheimer's disease. Ann Clin Transl Neurol 2015;2(07):769-773

14 Abner EL, Jicha GA, Shaw LM, Trojanowski JQ, Goetzl EJ. Plasma neuronal exosomal levels of Alzheimer's disease biomarkers in normal aging. Ann Clin Transl Neurol 2016;3(05):399-403

15 Russo I, Bubacco L, Greggio E. Exosomes-associated neurodegeneration and progression of Parkinson's disease. Am J Neurodegener Dis 2012;1(03):217-225

16 Marzesco A-M, Janich P, Wilsch-Bräuninger M, et al. Release of extracellular membrane particles carrying the stem cell marker prominin-1 (CD133) from neural progenitors and other epithelial cells. J Cell Sci 2005;118(Pt 13)2849-2858

17 Bellingham SA, Guo BB, Coleman BM, Hill AF. Exosomes: vehicles for the transfer of toxic proteins associated with neurodegenerative diseases? Front Physiol 2012;3:124 